\title{
Polymerizability of 1,3-Disubstituted 1,3-Butadiene and Preparation of New Alternating Copolymer
}

\author{
Mikiharu KAMACHI, Reijiro MiwA, \\ and Shun-ichi NOZAKURA \\ Department of Polymer Science, Faculty of Science, Osaka University, \\ 1-1 Machikaneyama, Toyonaka, Osaka 560, Japan.
}

(Received July 26, 1980)

\begin{abstract}
The polymerizabilities of ethyl trans-4-ethoxy-2,4-pentadienoate (EEP) and trans-4-ethoxy-2,4-pentadienonitrile (EPN) initiated by radical or ionic species were investigated. High-molecular-weight polymers were obtained from both monomers only by radical polymerization. Spectroscopic study showed the polymers to be composed of the 2,5-addition units of the corresponding monomers. The hydrogenation of these polymers gave alternating copolymers of ethyl vinyl ether with ethyl acrylate and of ketene with acrylonitrile, respectively.
\end{abstract}

KEY WORDS 1,3-Disubstituted 1,3-Butadiene / Ethyl trans-4-Ethoxy-2,4pentadienoate / trans-4-Ethoxy-2,4-pentadienonitrile / Radical Polymerization / Polymer Structure / Microtacticity / Hydrogenation / Alternating Copolymer /

Many papers have been published on the polymerization of butadiene and monosubstituted butadienes. ${ }^{1-4}$ However, little has been reported on the polymerization of 1,3-disubstituted butadienes. $^{5,6}$ If these dienes can be polymerized through a 1,4-type addition, the resulting polymers will be of interest not only as new types of diene polymers but also as precusors for new types of alternating copolymers, which can used as new polymeric materials. Consequently, we investigated the polymerizabilities of ethyl trans-4-ethoxy-2,4pentadienoate (EEP) and tran's-4-ethoxy-2,4pentadienonitrile (EPN) and their polymer structures. Since these monomers have

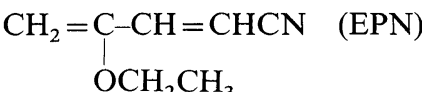

$$
\begin{aligned}
& \begin{aligned}
\mathrm{CH}_{2}= & \underset{l}{\mathrm{C}}-\mathrm{CH}=\mathrm{CHCOOC}_{2} \mathrm{H}_{5} \\
& \mathrm{OCH}_{2} \mathrm{CH}_{3}
\end{aligned}
\end{aligned}
$$

an ester or cyano group which stabilizes the propagating radical and anion at the 1 position of 1,3-diene, and an ether group which does not stabilize these at the 3 position of the monomer, the 1,4-addition polymer may be expected in the anionic or radical polymerization. High molecular-weight polymers were obtained from both monomers only by radical polymerization. The resulting polymers were composed of the 1,4-addition units of 1,3diene. The hydrogenation of the polymers led to the alternating copolymers of the ketene with acrylonitrile, or of the ethyl vinyl ether with ethyl acrylate.

\section{EXPERIMENTAL}

\section{Measurement}

Nuclear magnetic resonance (NMR) spectra were taken on a Varian A-60 or XL-100 spectrometer using tetramethylsilane as an internal standard. Infrared spectra (IR) were measured on a NihonBunko Model M9-35 spectrometer. Analytical gas chromatography was performed on a Shimadzu Model GC-2C gas chromatograph using $1.5 \mathrm{~m}$ Apiezone grease on cellite (carrier gas He; column temp, $\left.160^{\circ} \mathrm{C}\right)$.

\section{Materials}

4-Ethoxy-2,4-pentadienonitrile. 2-Ethoxy acrolein $(15.0 \mathrm{~g})$ was heated at reflux with cyanomethylenetriphenylphósphorane $(45.8 \mathrm{~g})$, prepared by the reaction of cyanomethyltriphenylphos- 
phonium chloride with sodium methoxide, ${ }^{7}$ in $150 \mathrm{ml}$ of chloroform for $5.5 \mathrm{~h}$. The reaction mixture was cooled, evaporated, and washed well with $500 \mathrm{ml}$ of petroleum ether to remove triphenylphosphine oxide. After stood $12 \mathrm{~h}$ at $0^{\circ} \mathrm{C}$, the oily layer was separated from triphenylphosphine oxide by decantation and concentrated. Rapid distillation in the presence of a small amount of hydroquinone gave $16.6 \mathrm{~g}$ (yield $78 \%$ ) of the diene consisting of a mixture of isomers, trans $/$ cis $=57 / 43$. bp $48-49^{\circ} \mathrm{C}$ $(1 \mathrm{mmHg}), n_{\mathrm{D}}^{20}=1.4963, d_{4}^{20}=0.9433$. UV (ethanol) $223\left(\varepsilon, 30001 \mathrm{~mol}^{-1} \mathrm{~cm}^{-1}\right)$ and $268 \mathrm{~nm}(\varepsilon, 7000$ $\left.1 \mathrm{~mol}^{-1} \mathrm{~cm}^{-1}\right)$. Anal. Calcd for $\mathrm{C}_{7} \mathrm{H}_{9} \mathrm{ON}$ : C, $68.27 \%$; H, 7.48\%; N, $11.43 \%$. Found: C, $68.24 \%$; $\mathrm{H}, 7.48 \%$; N, $11.43 \%$.

Preparation of ethyl trans-2,4-pentadienoate was done according to a published procedure. ${ }^{8} \mathrm{UV}$ (ethanol) $218 \mathrm{~nm}\left(\varepsilon, 85001 \mathrm{~mol}^{-1} \mathrm{~cm}^{-1}\right)$ and $270 \mathrm{~nm}$ $\left(\varepsilon, 13500 \mathrm{l} \mathrm{mol}^{-1} \mathrm{~cm}^{-1}\right)$.

The purity of the dienes was estimated to be more than $99.9 \%$ by gas chromatography.

\section{Polymerization}

The radical polymerization of EEP or EPN was carried out with 2,2'-azobisisobutyronitrile(AIBN) as an initiator in bulk or in benzene solution. The reaction mixture was placed in an ampoule and sealed under high vacuum. After given polymerization periods at given temperature, the corresponding polymers were obtained by precipitating the mixture from petroleum ether. The precipitates were collected by centrifugation and dried in vacuo. The polymers were purified twice by reprecipating the benzene solutions from petroleum ether. Anal. Calcd for $\mathrm{C}_{9} \mathrm{H}_{13} \mathrm{O}_{3}: \mathrm{C}, 63.51 \% ; \mathrm{H}$, $8.29 \%$. Found for poly(EEP): C, $62.91 \% \mathrm{H}, 8.44 \%$. Calcd for $\mathrm{C}_{7} \mathrm{H}_{9} \mathrm{ON}$ : C, $68.27 \% ; \mathrm{H}, 7.48 \% ; \mathrm{N}$, $11.43 \%$. Found for poly(EPN): C, $68.14 \%$; $7.59 \% ; \mathrm{N}, 11.27 \%$.

The copolymerization of above-mentioned monomers with styrene was performed with AIBN in benzene at $60^{\circ} \mathrm{C}$. Copolymers were isolated and purified by repeated reprecipitation from benzenemethanol system.

\section{Hydrogenation of the Polymer}

(a) $\operatorname{Poly}(E P N)$. Hydrogenation was carried out in a chloroform solution of the polymer by tris(triphenylphosphine)chlororhodium(I) under 1 atomosphere of hydrogen pressure and at room temperature. ${ }^{9}$ The reaction was continued until the stoichiometric uptake of hydrogen gas was completed. Hydrogenated poly(EPN) precipitated during the reaction. The precipitate was separated, dissolved in dimethyl sulfoxide, and reprecipitated from a large amount of acetone so as to remove any catalyst. This procedure was repeated twice.

(b) $\operatorname{Poly}(E E P)$. Hydrogenation was carried out in an ethanol solution of the polymer by palladium-charcoal under 1 atomosphere of hydrogen gas and at room temperature. ${ }^{10}$ After $20 \mathrm{~h}$, the solution of the polymer was separated from the palladium-charcoal by filteration, and the polymer was isolated from the filtrate by evaporation. The hydrogenated polymer was purified by repeated reprecipitation from a benzene-petroleum ether system.

\section{RESULTS AND DISCUSSION}

\section{Polymerizability of EEP and EPN}

The results of the polymerization of both monomers are shown in Table I. High-molecularweight polymers were obtained especially by the radical-initiation bulk-polymerization, whereas only viscous oligomers in low yields were obtained from EEP by anionic initiation and no polymer was obtained from EEP.

The high polymers of EEP were elastic, soluble in benzene, toluene, ethyl acetate, and acetone, and insoluble in hexane, petroleum ether and water. The polymer of EPN was soluble in acetone, acetonitrile, chloroform, dimethylformamide, and dimethyl sulfoxide, but insoluble in benzene, petroleum ether, ethyl alcohol, ethyl ether, and ethyl acetate.

In order to estimate the polymerizability of EEP or EPN, their copolymerizations with styrene or acrylonitrile were carried out at $60^{\circ} \mathrm{C}$ in benzene. The copolymer composition curves of EEP or EPN with styrene are shown in Figure 1. Conversions were kept below $5 \%$ in the copolymerization. Reactivity ratios were calculated using FinemanRoss and Kelen-Tüdos ${ }^{11}$ methods and shown in Table II. Since both methods lead to similar reactivity ratios in both copolymerization systems, a discussion on the monomer reactivity is possible; both EEP and EPN are more likely to be attacked by propagating radicals than styrene and acrylonitrile. The $Q$ and $e$ values of EEP are 3.08 and -1.64 , and those of EPN are 1.80 and -1.04 , respec- 
Polymerizability of 1,3-Disubstituted 1,3-Butadiene

Table I. The polymerization of EEP and EPN

\begin{tabular}{|c|c|c|c|c|c|c|c|c|}
\hline \multicolumn{2}{|c|}{ Monomers } & \multicolumn{2}{|c|}{ Initiators } & \multirow{2}{*}{ Solvents } & \multirow{2}{*}{$\frac{\text { Temp }}{{ }^{\circ} \mathrm{C}}$} & \multirow{2}{*}{$\frac{\text { Time }}{\mathrm{h}}$} & \multirow{2}{*}{$\frac{\text { Yield }}{\%}$} & \multirow{2}{*}[\eta]{} \\
\hline & & & & & & & & \\
\hline $\mathrm{EEP}^{\mathrm{a}}$ & 6.34 & AIBN & 4.56 & 一 & 60 & 71 & 27.8 & $1.20^{\mathrm{b}}$ \\
\hline $\mathrm{EEP}^{\mathrm{a}}$ & 6.34 & AIBN & 1.52 & - & 100 & 16 & 15.7 & $1.67^{\mathrm{b}}$ \\
\hline EEP & 0.81 & AIBN & 8.71 & Benzene & 60 & 24 & 21.7 & $0.11^{\mathrm{b}}$ \\
\hline EEP & 0.81 & AIBN & 8.76 & Ethyl acetate & 60 & 18 & 14.8 & $0.13^{b}$ \\
\hline $\mathrm{EEP}^{\mathrm{a}}$ & 6.34 & $\mathrm{BuLi}$ & 6.6 & - & 0 & 5 & Trace $^{d}$ & \\
\hline EEP & 0.94 & $\mathrm{BuLi}$ & 1.8 & THF & 0 & 5 & Trace $^{d}$ & \\
\hline EEP & 0.94 & $\mathrm{BuLi}$ & 1.8 & THF & -72 & 10 & Trace $^{\mathrm{d}}$ & \\
\hline EPN & 7.65 & AIBN & 3.75 & - & 60 & 24 & 11.4 & $0.42^{\mathrm{c}}$ \\
\hline EPN & 7.65 & AIBN & 16.2 & - & 60 & 24 & 27.2 & $0.46^{\mathrm{c}}$ \\
\hline EPN & 0.76 & AIBN & 4.76 & Benzene & 60 & 24 & 8.3 & $0.14^{\mathrm{c}}$ \\
\hline EPN & 7.36 & $\mathrm{BuLi}$ & 6.6 & - & 0 & 5 & - & \\
\hline EPN & 0.76 & $\mathrm{BuLi}$ & 1.8 & THF & -72 & 5 & - & \\
\hline
\end{tabular}

a Bulk polymerization; monomer, $1 \mathrm{ml}$.

b Benzene solution, at $30^{\circ} \mathrm{C}$.

c Acetone solution, at $30^{\circ} \mathrm{C}$.

d Viscous liquid.

tively. The $Q$ values of EEP and EPN are smaller than that of isoprene (3.33), ${ }^{3}$ indicating that the presence of the substituents at 1- and 3-positions of butadiene hardly influences the resonance of the $\pi$-electrons in the diene bond. The $e$ value of EEP is more negative than that of isoprene $(-1.23)^{3}$ or butadiene $(-1.05),{ }^{3}$ indicating that the electron-donating capacity of the ether group gets the better of the electron-accepting power of the ester group. The $e$ value of EPN is comparable to that of butadiene, showing that the participation of the ether group in the polarity was compensated by the cyano group

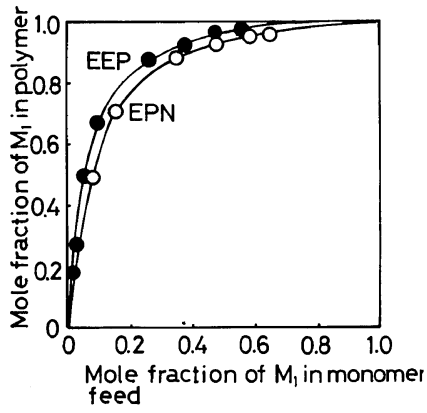

Figure 1. Variation of instantaneous copolymer composition with monomer-feed composition in the radical copolymerization of EEP or EPN with styrene at $60^{\circ} \mathrm{C}$ : , $\operatorname{EEP}\left(\mathrm{M}_{1}\right)-\mathrm{St}\left(\mathrm{M}_{2}\right) ; \mathrm{O}, \operatorname{EPN}\left(\mathrm{M}_{1}\right)-\mathrm{St}\left(\mathrm{M}_{2}\right) ;[\mathrm{AIBN}]=$ $3.0 \times 10^{-3} \mathrm{~mol} \mathrm{l}^{-1}$.

Table II. Monomer reactivity ratios for the radical copolymerizations of EEP or EPN $\left(\mathrm{M}_{1}\right)$ with other vinyl monomers

\begin{tabular}{|c|c|c|c|}
\hline $\begin{array}{c}\text { EEP } \\
r_{1}=12.2 \pm 3.4 \\
(14.7)^{\mathrm{b}}\end{array}$ & $\begin{array}{c}\text { Styrene }^{\mathrm{a}} \\
r_{2}=0.04 \pm 0.02 \\
(0.05)^{\mathrm{b}}\end{array}$ & $\begin{array}{c}\mathrm{EEP} \\
r_{1}=5.4 \pm 1.3 \\
(5.2)^{\mathrm{b}}\end{array}$ & $\begin{array}{c}\text { Acrylonitrile }^{\mathrm{a}} \\
r_{2}=0.01 \pm 0.01 \\
(0.00)^{\mathrm{b}}\end{array}$ \\
\hline $\begin{array}{l}\text { EPN } \\
r_{1}=11.8 \pm 2.3 \\
(8.2)^{\mathrm{b}}\end{array}$ & $\begin{array}{c}\text { Styrene }^{\mathrm{c}} \\
r_{2}=0.08 \pm 0.03 \\
(0.07)^{\mathrm{b}}\end{array}$ & & \\
\hline $\begin{array}{c}\text { Butadiene } \\
r_{1}=1.4\end{array}$ & $\begin{array}{l}\text { Styrene }^{\mathrm{d}} \\
r_{2}=0.5\end{array}$ & $\begin{array}{c}\text { Butadiene } \\
r_{1}=0.3\end{array}$ & $\begin{array}{c}\text { Acrylonitrile }^{\mathrm{e}} \\
r_{2}=0.075\end{array}$ \\
\hline
\end{tabular}

a Solvent, benzene; polymerization temp, $60^{\circ} \mathrm{C}$.

b Monomer reactivity ratio estimated by Kelen-Tüdos method.

c Solvent, methyl ethyl ketone; polymerization temp, $60^{\circ} \mathrm{C}$.

d From reference 4, p II-155.

e From reference 4, p II-153. 
which is stronger as an electron-withdrawing group than the ester group.

\section{Structure of the Polymers}

The structure of poly(EEP) was investigated using the high-molecular-weight polymer obtained by radical initiation. As for the three IR peaks of the monomer, i.e., 1570, $1625\left(v_{\mathrm{C}=\mathrm{C}}\right)$ and $1705\left(v_{\mathrm{C}=\mathrm{O}}\right)$ $\mathrm{cm}^{-1}$, the first one disappeared and the latter two shifted to 1660 and $1735 \mathrm{~cm}^{-1}$ in the case of the polymer. Although there are three possible addition-modes in the polymerization (2,5-, 2,3-, and 4,5-addition), the polymer was found to be composed of the 2,5-addition structure from the following spectroscopic results. The IR absorption at $1735 \mathrm{~cm}^{-1}$ of the polymer is assignable to the
$\mathrm{C}=\mathrm{O}$ bond of saturated esters. ${ }^{12}$ The ${ }^{1} \mathrm{H}$ NMR spectrum of the polymer shows resonances at $\delta 1.12$ $(6 \mathrm{H}), 2.74(2 \mathrm{H}), 3.52(3 \mathrm{H}), 4.07(3 \mathrm{H})$ and $4.75(1 \mathrm{H})$ ppm. (Figure 2) The resonances were assigned respectively to protons of $\mathrm{CH}_{3}-,-\mathrm{CH}_{2}-$ (main chain), $-\mathrm{OCH}_{2}-,-\mathrm{COOCH}_{2}$ and $-\mathrm{CH}-$, and $-\mathrm{CH}=$. This assignment was confirmed by decoupling of the methyl protons. The ratio of the olefinic protons to methyl protons $(1: 6)$ shows that the 2,5-addition is predominant, since 2,3- and 4,5-addition leads to a different ratio $(1: 3)$. The ${ }^{13} \mathrm{C}$ NMR spectrum supports the view that the polymer was formed by 2,5-addition, since only two olefinic carbon resonances and carbonyl carbon resonance were in each region. ${ }^{13}$ (Figure 3).

As for the IR peaks of EPN, i.e., 1570, 1625

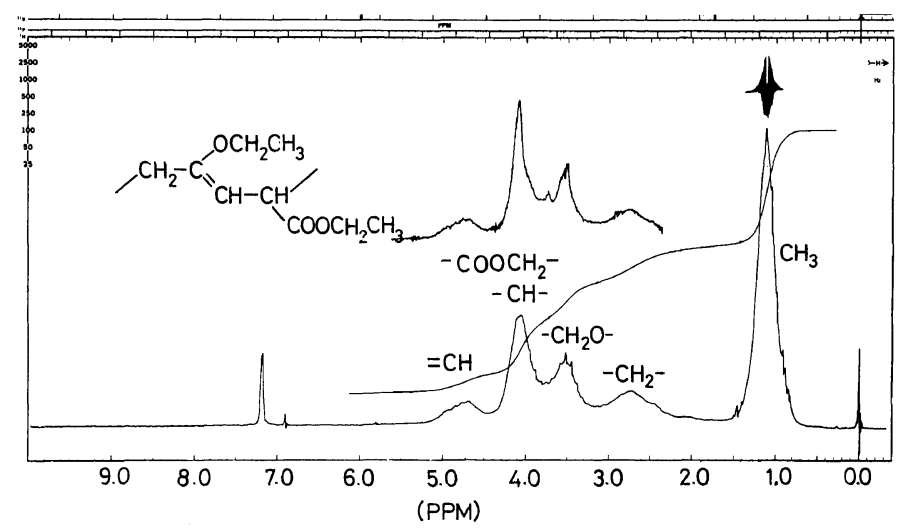

Figure 2. The ${ }^{1} \mathrm{H}$ NMR spectrum of poly(EEP); $10 \% \mathrm{C}_{6} \mathrm{D}_{6}$ solution.

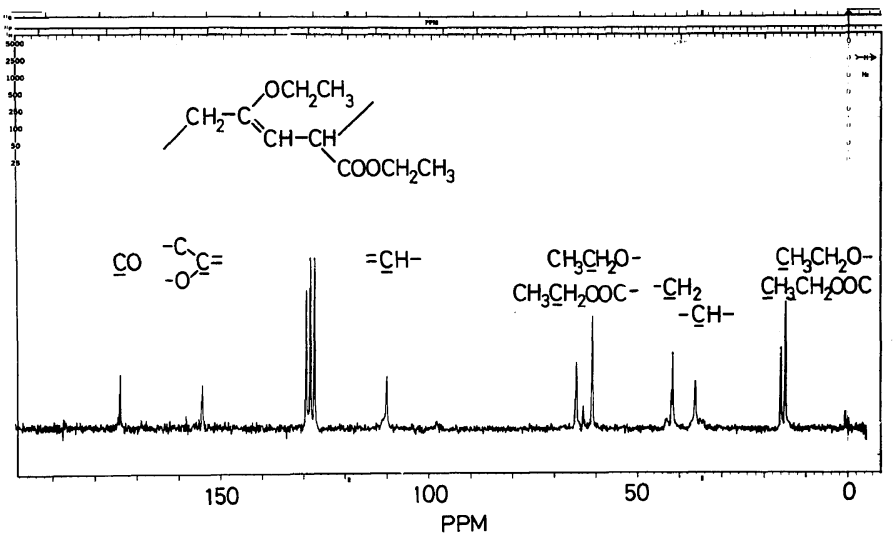

Figure 3. The ${ }^{13} \mathrm{C}$ NMR spectrum of poly $(\mathrm{EEP}) ; 10 \% \mathrm{C}_{6} \mathrm{D}_{6}$ solution. 


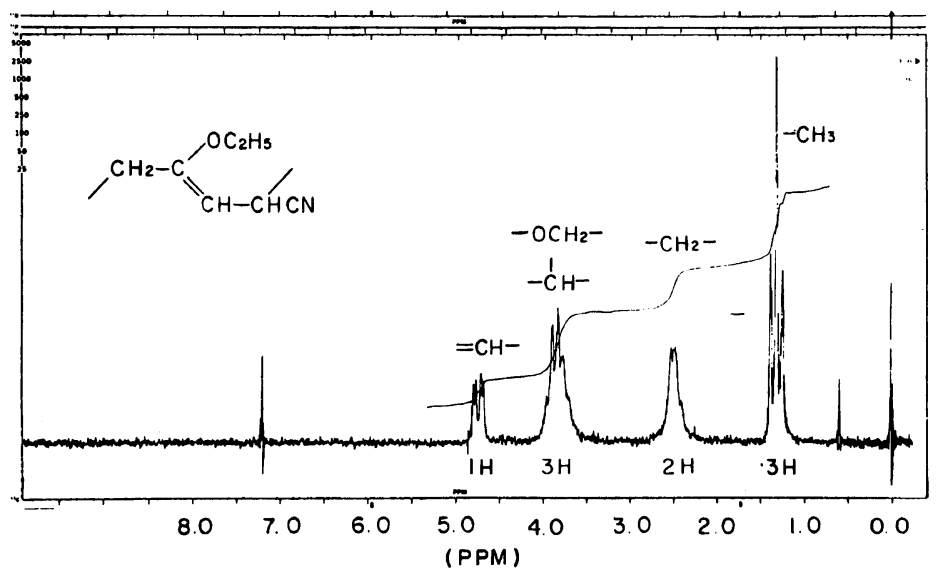

Figure 4. The ${ }^{1} \mathrm{H}$ NMR spectrum of poly(EPN); $5 \% \mathrm{CDCl}_{3}$ solution.

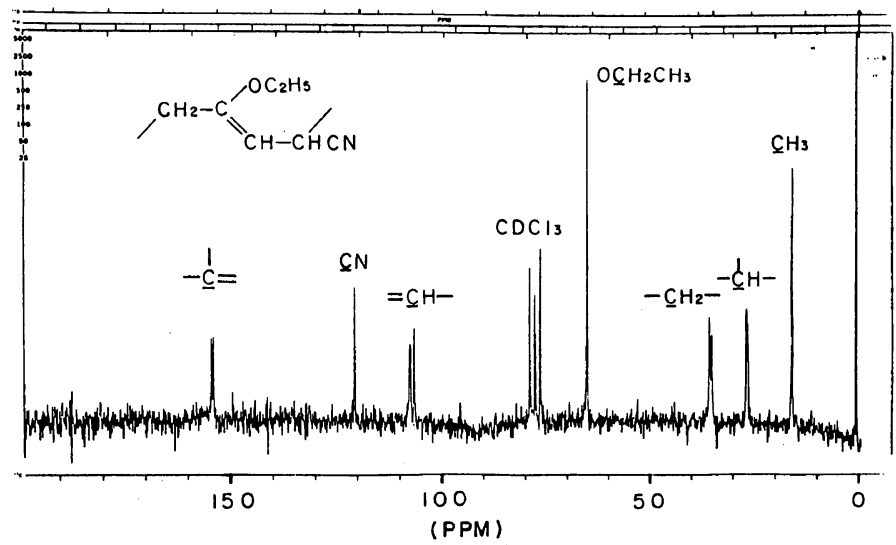

Figure 5. The ${ }^{13} \mathrm{C}$ NMR spectrum of poly $(\mathrm{EPN}) ; 5 \% \mathrm{CDCl}_{3}$ solution.

$\left(v_{\mathrm{C}=\mathrm{C}}\right)$ and $2230\left(v_{\mathrm{C}=\mathrm{N}}\right) \mathrm{cm}^{-1}$, the first one disappeared and the latter two shifted to 1670 and 2250 $\mathrm{cm}^{-1}$ in the poly(EPN), respectively. Since the shift of the two peaks of the functional groups to higher wave number is considered due to the decrease in the resonance of the groups with double bond in the polymer, ${ }^{12}$ the IR spectra seem to indicate that the polymer is comprised mainly of 2,5- and 2,3additions. The ${ }^{1} \mathrm{H}$ NMR spectrum of the polymer shows resonances at $\delta 1.5(\mathrm{t}, 3 \mathrm{H}), 2.4(\mathrm{~d}, 2 \mathrm{H}), 3.5$ $4.0(\mathrm{~m}, 3 \mathrm{H})$ and $4.8(\mathrm{q}, 1 \mathrm{H}) \mathrm{ppm}$. These resonances were assigned respectively to $\mathrm{CH}_{3}-,-\mathrm{CH}_{2}-$ (main chain), $-\mathrm{OCH}_{2}-$ and $-\mathrm{CH}-$, and $-\mathrm{CH}=$ (Figure 4). The fact that the ratio of olefinic protons to the methyl protons is $1: 3$ shows that the 2,5 -addition is predominant, since other additions lead to a different ratio $(2: 3)$. Two doublet resonances of the olefinic proton collapsed to two singlet lines by means of decoupling the methine group. This indicates that there are two kinds of olefinic protons caused by two configurations (cis and trans) of the olefinic bond in the main chain or by two configurations of the asymmetric methine carbon. However, the latter interpretation can be ruled out from the Stuart model investigation in which the olefinic proton is not magnetically influenced by the $R$ or $S$ configuration of the methine carbon. The ${ }^{13} \mathrm{C}$ NMR spectrum and the assignment of the re- 
sonance lines are shown in Figure 5. Resonances due to carbons of side groups $\left(\mathrm{CH}_{3}, \mathrm{CH}_{2} \mathrm{O}\right.$ and $\left.\mathrm{CN}\right)$ each has a single line in the resonance region and resonances due to the main-chain carbons are split into two resonance lines. These results may be explained by the possible cis and trans configurations of the olefinic carbons in the main chain. Thus, ${ }^{13} \mathrm{C}$ NMR also supports that the polymer is composed of the 2,5 -addition.

\section{Hydrogenation of the Polymers}

(a) Hydrogenation of Poly(EEP). The IR absorptions due to the $\mathrm{C}=\mathrm{C}$ bond completely disappeared following the hydrogenation. As shown in Figures 6 and 7, the NMR peaks at $4.75 \mathrm{ppm}\left({ }^{1} \mathrm{H}\right.$, olefinic proton), 110 and $115 \mathrm{ppm}\left({ }^{13} \mathrm{C}\right.$, olefinic carbons) completely disappeared after hydrogenation. Since the NMR spectrum of the hydrogenated polymer was exactly the same as the well-defined NMR spectra of poly(ethyl vinyl ether) and poly(ethyl acrylate), ${ }^{13}$ the polymer obtained is thus an alternating polymer of vinyl ether and ethyl acrylate. The hydrogenated polymer is soluble in benzene, ethyl ether, and chloroform, but insoluble in ethyl alcohol, petroleum ether, and water.

(b) Hydrogenation of the Poly (EPN). Since the poly(EPN) did not dissolve in benzene or ethyl alcohol, the Willkinson catalyst was employed in chloroform for the hydrogenation of the polymer instead of palladium charcoal. After hydrogenation,

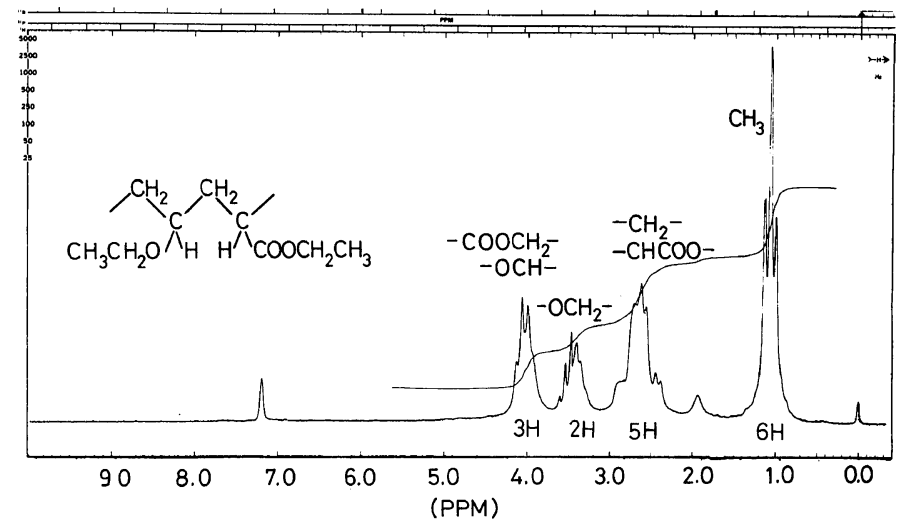

Figure 6. The ${ }^{1} \mathrm{H}$ NMR spectrum of the hydrogenated poly(EEP); $10 \% \mathrm{C}_{6} \mathrm{D}_{6}$ solution.

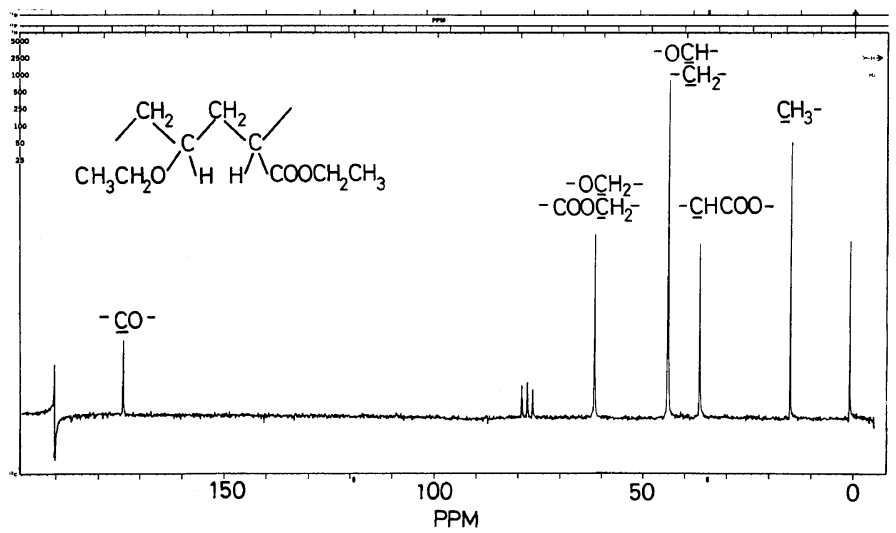

Figure 7. The ${ }^{13} \mathrm{C}$ NMR spectrum of the hydrogenated poly(EEP); $10 \% \mathrm{C}_{6} \mathrm{D}_{6}$ solution. 
Polymerizability of 1,3-Disubstituted 1,3-Butadiene

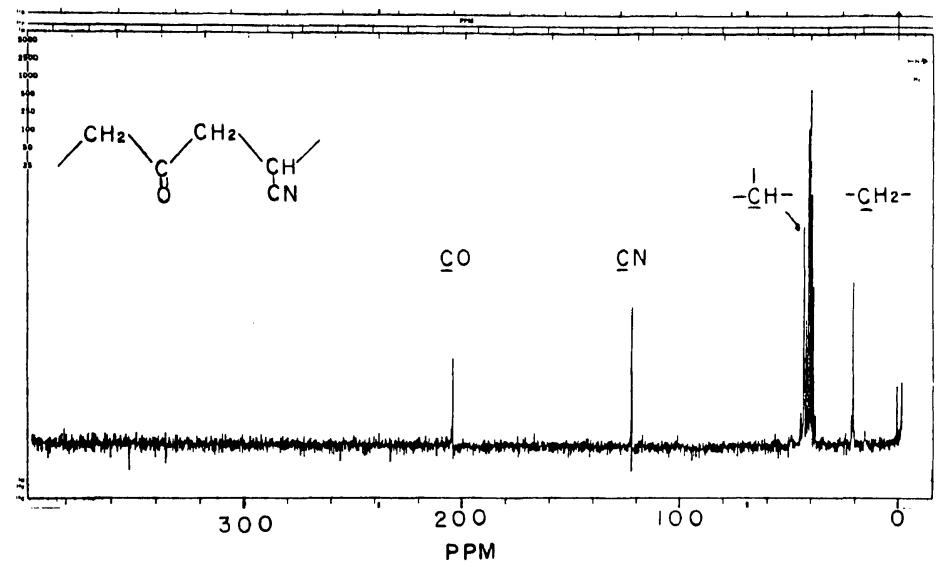

Figure 8. The ${ }^{13} \mathrm{C}$ NMR spectrum of the hydrogenated poly(EPN); $5 \%$ DMSO- $d_{6}$ solution.

the IR absorptions due to the $\mathrm{C}=\mathrm{C}$ bond at 1632 and $1575 \mathrm{~cm}^{-1}$ disappeared and the absorption due to the $\mathrm{C}=\mathrm{O}$ bond appeared at $1730 \mathrm{~cm}^{-1}$. The ${ }^{13} \mathrm{C}$ NMR spectrum of the hydrogenated polymer showed 22.0, 44.7, 123.5, and $205.8 \mathrm{ppm}$ which were assigned to carbons of $-\mathrm{CH}_{2}^{-},-\mathrm{CH}-,-\mathrm{CN}$, and $-\mathrm{C}=\mathrm{O}$, respectively (Figure 8 ). Since the hydrogenation of $-\mathrm{C}=\mathrm{C}-\mathrm{OR}$ ( $\mathrm{R}$, alkyl) with the Willkinson catalyst is reported to lead to $-\mathrm{C}-\mathrm{C}_{\text {II }}-{ }^{14}$ the hydrogenated polymer is considered to be composed of $-\left(-\mathrm{CH}_{2}-\underset{\|}{\mathrm{C}}-\mathrm{CH}_{2}-\mathrm{C} H-\right)_{n}-$. The elemental analysis of the polymer supports the polymers is being an alternating copolymer of ketene and acrylonitrile.

\section{REFERENCES}

1. W. Cooper and G. Vaugham, "Progress in Polymer Science," Vol. 1, A. D. Jenkins, Ed., Pergamon Press, Oxford, 1967, pp 93-160.

2. G. Natta and L. Porri, "Polymer Chemistry of Synthetic Elastomer," Part 2, J. P. Kennedy and E. G. Tornqvist, Ed., Wiley-Interscience, New York,
N.Y., 1969, pp 597-678.

3. L. J. Young, "Polymer Handbook," 2nd ed, J. Brandrup and E. H. Immergut, Ed., Wiley-Science, New York, N.Y., 1975, Chapter II, pp 105-404.

4. E. C. Leonard, "Vinyl and Diene Monomers," Part 2, E. C. Leonard, Ed., Wiley-Interscience, New York, N.Y., 1970.

5. Y. Imanishi, S. Kanagawa and T. Higashimura, Makromol. Chem., 175, 1761 (1974).

6. K. Hasegawa, R. Asami, and T. Higashimura, Macromolecules, 10, 585 (1977).

7. S. Trippertt and D. M. Walber, J. Chem. Soc., 3874 (1959).

8. W. C. Agosta and W. W. Lawrence, Jr., J. Org. Chem., 35, 3851 (1970).

9. Org. Synth., 3, 685 (1955).

10. L. J. Bellamy, "The Infrared Spectra of Complex Molecules," Methuen, London, 1958, pp 178-191.

11. T. Kelen and F. Tüdos, J. Macromol. Sci., Chem., A9, 1 (1975).

12. J. B. Stothers, "Carbon-13 NMR Spectroscopy," Academic Press, New York, N.Y., 1972, pp 183-195 and pp 279-310.

13. F. A. Bovey, "High Resolution NMR of Macromolecules," Academic Press, New York, N.Y., 1972.

14. A. J. Birch and K. A. M. Walker, J. Chem. Soc. Sect C, 1894 (1966). 